\title{
Effect of channelling on hydrostatic pressure behind a haptic lens
}

\author{
W. BERGMAN*, D. M. MAURIGE†, AND M. RUBEN \\ From the Department of Physiology, Institute of Ophthalmology, University of London, \\ and the Contact Lens Department, Moorfields Eye Hospital, High Holborn Branch, London
}

The fluid beneath a well-fitting haptic lens with no channel or fenestration is believed to remain perfectly sealed off. This is known to lead to the corneal surface being deprived of oxygen with consequent oedema and clouding (Smelser, 1952; Kinsey, 1952). A contributory cause for the corneal distress may be the development of a negative pressure under the lens; this appears to be present since many such lenses appear to cling to the eye and resist removal.

The purpose of the experiments described here was to determine the fluid pressure behind a flush-fitting lens and its variation with eye movements, and to see how it was affected by channelling.

The tests were of a preliminary nature and were carried out on one subject only.

\section{Methods}

A hydrogel impression of the eye was taken, and a stone cast made from it. A o.6-mm.-thick shell moulded from Acrylic $\ddagger$ was fitted to make contact over at least half the corneal surface and was hand-worked to give a transition with limbal clearance (Ruben, 1967). This lens is denoted $A$; an identical shell $A_{1}$ was prepared with an inferior-nasal channel. Three other shells, $B, B_{1}$, and $B_{2}$, were also fabricated with none, one, and two channels respectively. These were similar to A, but had a central back optic 0.6 flatter than $\mathrm{K}(\mathrm{K}=7.8 \mathrm{H})$ polished onto this surface and the haptic settled back until corneal contact was achieved.

A small hole was drilled in these shells at the limbal transition zone into which was cemented a short length of polyethylene tubing§ which connected the fluid to the manometer. This tubing was cold-stretched over a few $\mathrm{cm}$. near its connection to the lens in order to increase its flexibility. The hydrostatic pressure was measured with a Sanborn pressure transducer which was prepared as described by Hedbys, Mishima, and Maurice (1963) to approach the volume displacement of $0.05 \mathrm{~mm} .3 / 100 \mathrm{~mm}$. Hg claimed by the manufacturers. No attention was paid to temperature control of the system owing to the less stringent conditions of operation.

To conduct an experiment the manometer was adjusted so that the lens could be placed in a suitable position with the connecting tube exerting the least possible traction upon it. The shell was turned face down and filled with saline, and the recording manometer set to zero pressure. An index mark was made on a vertical mirror at the level of the saline meniscus, so that the subject by observing his own eye opposite this mark would ensure that no differences in fluid level were introduced into the recording system. The true hydrostatic pressure behind the lens could then be read directly from the manometer recording. Before the experiment the calibration was established by altering the height of the saline-filled contact lens shell from its zero position by definite amounts. The baseline was checked for drift at the end of each run.

Received for publication January 20, 1970

Address for reprints: Mr. M. Ruben, Contact Lens Department, Moorfields Eye Hospital, High Holborn, London, W.C. I

*Columbia University Medical School. Fight-for-Sight Student, Fellow of the National Council to Combat Blindness, Inc., N.Y. †Present address: Division of Ophthalmology, Stanford University Medical School

†Imperial Chemical Industries, polymethacrylate C.Q.I.

$\S$ Portex polyethylene tubing No. 270 
When the equipment was prepared, the lens was inserted into the eye and allowed to settle with the eye looking forward. When the pressure had become established the eye was rotated, either slowly or quickly, as far as its extreme positions.

The correct operation of the system could be checked by the subject raising and lowering his head by a few $\mathrm{cm}$. from the zero position when appropriate deflections of the recorder occurred.

\section{Results}

With the eye in the primary position, a negative pressure behind the lens was immediately developed and was maintained. Its magnitude was generally between 2 and $3 \mathrm{~cm} . \mathrm{H}_{2} \mathrm{O}$, regardless of whether the lens was channelled or not.

Movements of the eye either had no effect or increased the suction. The changes were never more than $10 \mathrm{~cm} . \mathrm{H}_{2} \mathrm{O}$ initially and lessened gradually if the position was maintained. In this subject, nasally directed movements produced the greatest effect. Slower movements appeared to cause lesser changes, and channelling tended to diminish the responses slightly. The pressure never became zero or positive on returning to the forward direction.

Blinking caused a sharp excursion of variable extent and in either direction. Forcible closure of the lids was also variable in its effects, but generally tended to increase the suction behind the lens. The recordings are shown in the Figure.

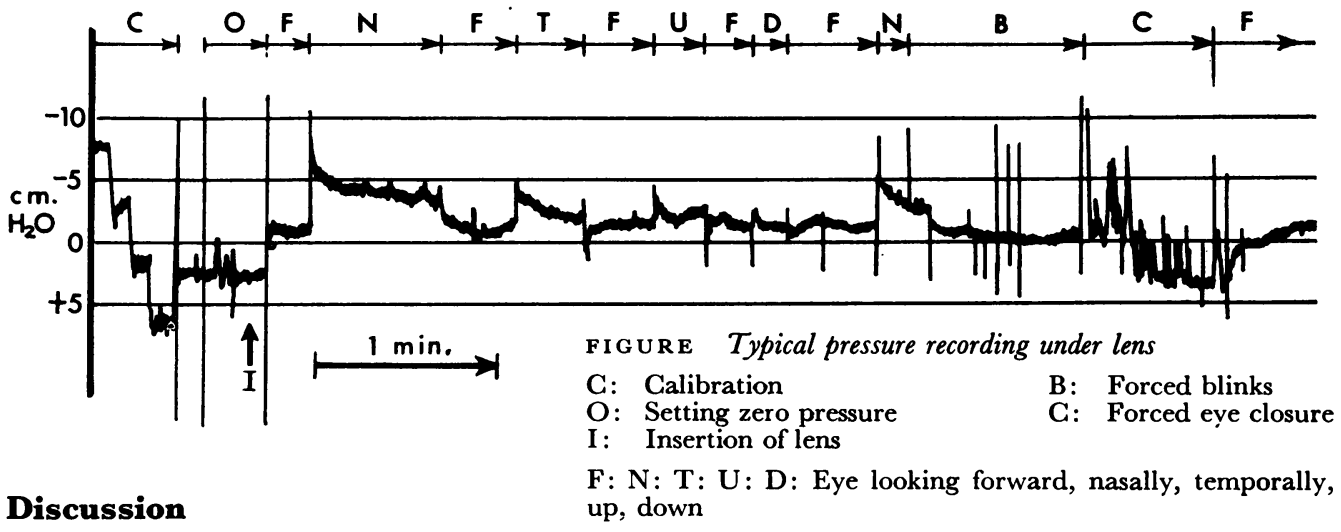

Though the lenses appeared to be an acceptable fit and their behaviour may well be representative of similar well-fitted lenses, the results should be accepted with caution since they were derived from a single subject. It appears that the suction beneath the lens never becomes strong enough to be of significance in the mechanical stability of the epithelium, bearing in mind that the hydrostatic pressure in the stroma on the other face of the cellular membrane is of the order of $-5^{0} \mathrm{~cm} . \mathrm{H}_{2} \mathrm{O}$ in the normal cornea (Hedbys and others, 1963).

It may also be noted that channelling appears to have no marked effect upon this pressure, so that any benefit it confers is likely to be only by way of increasing the circulation of tear fluid under the lens and hence the access of oxygen to the cornea.

We should like to thank Miss Anna van der Ham who was the subject in these tests.

\section{References}

hedbys, B. O., Mishima, s., and MAURICE, D. M. (1963) Exp. Eye Res., 2, 99

KINSEy, v. E. (1952) Amer. 7. Ophthal., 35, 69 I

RUBEN, м. (1967) Trans. ophthal. Soc. U.K., 87, 643

Smelser, G. K. (1952) Arch. Ophthal. (Chicago), 47, 328 